\title{
DIRECTIONAL FLOW OF FALLOPIAN TUBE SECRETION IN THE ROMNEY EWE
}

\author{
A. R. BELVE AND M. F. McDONALD \\ Department of Sheep Husbandry, Massey University, \\ Palmerston North, New Zealand
}

(Received 3rd March 1967, revised 25th Fuly 1967)

\begin{abstract}
Summary. The continuous collection of fluid flowing from both ends of the Fallopian tube of the ewe was attempted by placing a cannula in the ovarian end of the ampulla and a further cannula passing through the wall of the corresponding uterine horn and opposed to the uterotubal junction. Daily recordings of fluid were made in thirty ewes over a period ranging from 3 to 106 days; observations were also made for oestrous behaviour.

There was an increase in total output of tubal fluid starting on the last day of the oestrous cycle and reaching a maximum about Day 2, after which a gradual decline occurred. A greater part of the total fluid secreted flowed through the ampullar end. Flow through the utero-tubal junction into the uterus remained low for most of the cycle, but markedly increased in all cycles $3 \cdot 9 \pm 0 \cdot 1$ days after the onset of oestrus.

The peak flow through the utero-tubal junction would therefore appear to coincide with the time during which ova enter the uterus in the ewe.
\end{abstract}

\section{INTRODUCTION}

A variety of methods has been used to observe movements of the Fallopian tube and their effect on sperm and ovum transport, for example, direct observation of the tubes (Westman, 1926), utero-tubal insufflation (Bonnet, 1964), passage of radiopaque materials (Bjork, 1959) and the passage of natural ova (Wintenberger, 1953; Greenwald, 1961) and artificial ova (Harper, Bennett, Boursnell \& Rowson, 1960).

Several recent studies have associated the secretion of fluid within the Fallopian tube with the mechanism of ovum movement through the isthmus and entry into the uterus. Thus, in the rabbit (Black \& Asdell, 1959), sheep (Edgar \& Asdell, 1960) and cow (Black \& Davis, 1962), experiments involving ligation of the ovarian end of the tube showed in each case that fluid accumulated in the lumen for 3 days after the onset of oestrus but then rapidly disappeared. Black \& Asdell (1958) suggested that the ova are carried into the uterus by 'a fluid surge' but Black \& Davis (1962) later reported that, with the 
cow, the fluid surge preceded the expected time of ovum transit into the uterus by about $24 \mathrm{hr}$.

In view of these reports, an attempt has been made quantitatively to assess the movement of tubal fluids in the sheep by using a modification of the cannulation technique described by Clewe \& Mastroianni (1960). This technique was adopted since it allowed repeated observations to be made on the same animal and avoided the disadvantages of methods involving post-mortem examination of fluid in the genital tract.

\section{MATERIALS AND METHODS}

Animals

Thirty 4- and 6-year-old Romney ewes were used during the period April to July, 1966. The ewes were kept in individual pens arranged so that a vasectomized ram was in contact with each ewe but prevented from mating by the wire netting partition. Observations for oestrous behaviour and flow of vaginal mucus were made at frequent intervals during daylight hours. The onset of oestrus was recorded when the ewe's behaviour and the activity of the ram suggested that mating would occur. Where oestrous behaviour was doubtful (five cycles) oestrus was presumed to have occurred when characteristic changes in the flow of mucus were detected (Radford \& Watson, 1955). The ram was periodically replaced in an attempt to ensure active interest in the ewes.

\section{Operational procedure}

Each animal was tranquillized with chlorpromazine and anaesthetized with Nembutal. The genital tract was exposed by a mid-ventral incision anterior to the mammary glands and the size and number of corpora lutea and follicles were noted.

The abdominal wall was punctured with a stainless steel trochar at a point $15 \mathrm{~cm}$ lateral to the dorsal mid-line and $15 \mathrm{~cm}$ anterior to the stifle joint. Two cannulae (43-cm lengths of transparent vinyl tubing; internal diameter $1.5 \mathrm{~mm}$; external diameter $2.5 \mathrm{~mm}$ ), filled with isotonic saline containing heparin and penicillin, were passed through the trochar and into the abdominal cavity. The trochar was then withdrawn and the flank wound closed with a purse string suture leaving about $6 \mathrm{~cm}$ of each cannula protruding.

The flanged end of one cannula was ligated into the fimbrial end of the ampulla by a single atraumatic No. 6 braided silk ligature, while the other cannula was passed through the uterine wall approximately $4 \mathrm{~cm}$ below the utero-tubal junction and ligated into a position opposed to this junction. During insertion of the ligatures care was taken to avoid undue interference with blood vessels. Penicillin was placed in the abdominal cavity and the body wall closed.

\section{Collection of fluid}

A collection device similar to that described by Black, Druby \& Riesen (1963) was used. It consisted of two polythene collection tubes $(7 \mathrm{~mm}$ internal diameter; $9 \mathrm{~mm}$ external diameter and $10 \mathrm{~cm}$ in length) attached to a block of plywood $(10 \times 6 \times 0.6 \mathrm{~cm})$. To the base of each collection tube was fitted a 
thimble-shaped rubber cone and to the top a polyethylene adaptor. A fine hole at the top of each collection tube allowed maintenance of atmospheric pressure.

The collection device was placed $5 \mathrm{~cm}$ below the point where the cannulae emerged on the flank and sutured to the skin at each corner. The cannulae, previously marked for identification, were connected to the appropriate collection tube. Fluid accumulating in the collection tube was removed daily (08.30 hours) and measured, using a 1-ml hypodermic syringe inserted through the rubber cone.

\section{Post-mortem and histology}

Ten ewes in which the cannulae functioned successfully were slaughtered at the completion of their recording periods and the Fallopian tubes were fixed in Bouin's fluid. Tissues from the mid-ampulla and mid-isthmus of the cannulated and non-cannulated Fallopian tubes of each animal were embedded in paraffin wax; sections were cut at 8 to $10 \mu$ and stained with haematoxylin and eosin. Measurements of epithelial cell height (five fields in each of two sections) were made on each sample of tissue.

\section{RESULTS}

\section{Period of collection}

As judged by the presence of a continuous column of fluid in the cannulae and accumulation of fluid in the collection tubes, both cannulations were successful in all ewes, at least initially. In the thirty ewes, the average period following surgery, during which fluid was obtained from both cannulae, was $33 \cdot 8$ days (range 3 to 106 days).

Eleven ewes did not contribute fluid through both cannulae during a complete oestrous cycle for a variety of causes, i.e., failure to maintain a flow of fluid for the full experimental period (five ewes), salpingitis (two ewes), death (one ewe), damage to cannula (one ewe) and anoestrus (two ewes).

The remaining nineteen animals provided data on fluid secreted during a total of twenty-six oestrous cycles. Data has not been included in the analysis where oestrus occurred within 7 days of operation since it seemed that secretion of fluid at this critical period of the study would still be seriously influenced by surgery. As the experiment progressed cannulation of the isthmic end of the Fallopian tube often failed. However, both cannulae in each of four animals were still functioning successfully when observations were terminated.

\section{Fluid secreted}

The mean daily fluid secretion is shown in Text-fig. 1. Fluid secretion increased on the last day of the oestrous cycle, reaching a maximum of 1.18 $\mathrm{ml} / 24 \mathrm{hr}$ (range 0.77 to $1.61 \mathrm{ml}$ ) on Day 2, that is about $24 \mathrm{hr}$ after the onset of behavioural oestrus. Thereafter the amount of fluid produced showed a sharp decline until about Day 6. In all oestrous cycles recorded, except for two (different sheep), there was a transient rise in the level of fluid secreted within the range of Days 6 to 10 (mean Day 7). On succeeding days fluid secretion again gradually declined reaching a low level of $0.20 \mathrm{ml} / 24 \mathrm{hr}$ (range 0.03 to $0.46 \mathrm{ml}$ ) on Day 15. 
Following the analyses of variance, daily means of fluid secreted were ranked in ascending order and differences tested using Duncan's multiple range test (Duncan, 1955). For simplicity, only the differences between the means of

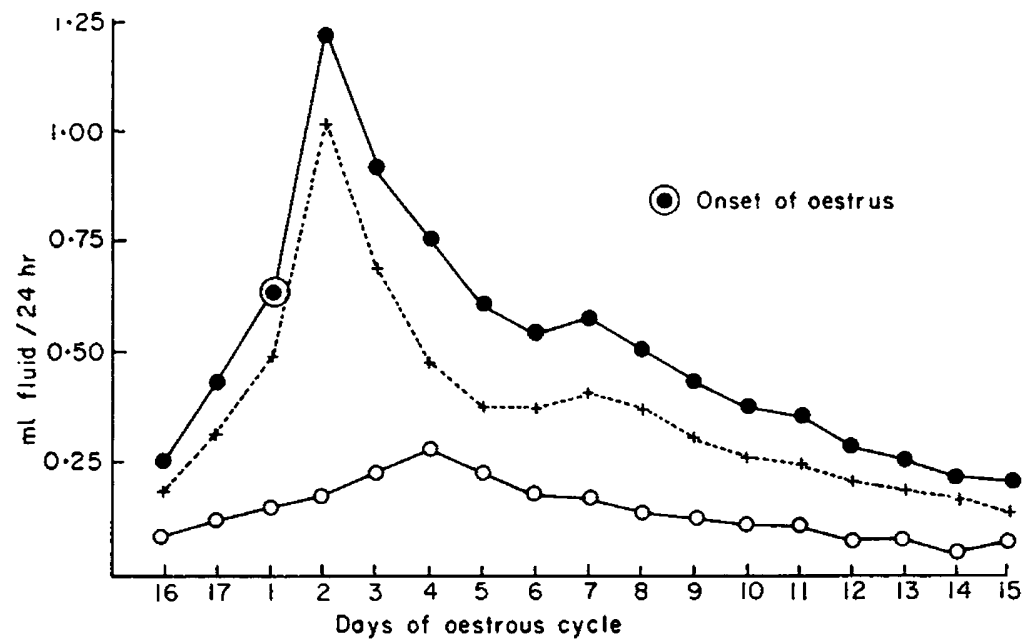

Text-Fig. 1. Total output (-) of tubal fluid and flow through the ovarian (ampullar, + ) and uterine (isthmic, $O$ ) ends of the Fallopian tube of the ewe.

successive days of the cycle are considered. On this basis differences between adjacent days from 16 to 5 inclusive were significant $(P<0.01)$.

The analyses of variance of fluid secreted daily and also total volume of fluid secreted over each individual oestrous cycle are presented in Table 1.

TABLE 1

SUMMARY OF ANALYSES OF VARIANGE FOR FLUID SEGRETED AND FLUID FLOW $(\mathrm{ml} / 24 \mathrm{hr})$

\begin{tabular}{|c|c|c|c|c|}
\hline Source & $d . f$. & $\begin{array}{l}\text { Fluid } \\
\text { secreted } \\
\text { M.S. }\end{array}$ & $\begin{array}{c}\text { Ampullar } \\
\text { flow } \\
\text { M.S. }\end{array}$ & $\begin{array}{c}\text { Isthmic } \\
\text { flow } \\
\text { M.S. }\end{array}$ \\
\hline $\begin{array}{l}\text { Between days } \\
\text { Between sheep } \\
\text { Between cycles, within sheep } \\
\text { Error }\end{array}$ & $\begin{array}{r}16 \\
18 \\
7 \\
394\end{array}$ & $\begin{array}{l}1 \cdot 840^{* *} \\
0.248 \\
0 \cdot 141^{* *} \\
0.046\end{array}$ & $\begin{array}{l}1 \cdot 256^{* *} \\
0.265 \\
0.204^{* *} \\
0.025\end{array}$ & $\begin{array}{l}0.109^{* *} \\
0.034 \\
0.049^{* *} \\
0.011\end{array}$ \\
\hline
\end{tabular}

Data; nineteen ewes, $20 \times 17$-day cycles; $6 \times 16$-day cycles. M.S. = Mean square.

$* * P<0.01$.

The main source of variation in fluid secretion accrued from differences between days of the cycle $(P<0.01)$. Data from three ewes with four, three and three cycles, respectively, indicated that considerable variation also occurred between cycles within sheep $(P<0.01)$.

\section{Direction of flow}

The mean flow, in $24 \mathrm{hr}$, through the abdominal tubal ostium and into the abdominal cavity (designated ampullar flow) and that through the uterotubal junction into the uterus (isthmic flow) are shown in Text-fig. 1. 
Ampullar flow closely paralleled fluid secretion and for each day of the oestrous cycle the greater part of the fluid secreted entered the abdominal cavity. Maximum ampullar flow of $1.01 \mathrm{ml} / 24 \mathrm{hr}$ (range 0.55 to $1.44 \mathrm{ml}$ ) occurred about Day 2 of the cycle, while a minimal mean flow of $0.13 \mathrm{ml} / 24 \mathrm{hr}$ (range 0.01 to $0.35 \mathrm{ml}$ ) occurred on Day 15 of the cycle.

Duncan's multiple range test indicated that the adjacent Days 16, 17, 1, 2 and 3 differed significantly $(P<0.01)$ in their mean flow. Analyses of variance (Table 1) again indicated 'day' of the cycle was the major source of variation $(P<0.01)$, while a minor source of variance was due to differences between cycles within sheep $(P<0.01)$.

Changes in the rate of flow through the utero-tubal junction also occurred in a cyclic manner. Peak isthmic flow of $0.28 \mathrm{ml} / 24 \mathrm{hr}$ (range 0.17 to $0.84 \mathrm{ml}$ ) occurred $3 \cdot 9 \pm 0 \cdot 1$ days (range Day 3 to 6 ) following the onset of oestrus; but, for the greater part of the cycle, flow of fluid into the uterus remained low. The increase in isthmic flow taking place in most animals was transient in nature, seldom exceeding 3 days in duration. In sixteen of the cycles, fluid from the isthmic cannula during these 3 days was red in colour contrasting markedly with the clear appearance of this fluid over the remainder of the cycle and fluid of the ampullar flow.

The mean isthmic flow on Days 2, 3 and 4 of the cycle were the only adjacent days significantly different $(P<0 \cdot 05)$. However, peak isthmic flow on Day 4 was significantly greater $(P<0 \cdot 01)$ than the flow on Day 2 and on Day 6 . Day of the cycle was the major source of variation in isthmic flow as was the case with ampullar flow.

\section{Histology}

Examination of the sections taken from the mid-ampulla and mid-isthmus did not reveal any morphological differences between the cannulated and noncannulated Fallopian tube of the same animal. Mean epithelial cell height of cannulated versus non-cannulated Fallopian tubes did not differ significantly for the mid-ampulla $(F<1)$ or the mid-isthmus $(F<1)$.

\section{DISCUSSION}

The present investigation confirms previous findings of a well-defined cyclic pattern of fluid secretion in the Fallopian tube of the ewe. The levels recorded at oestrus are less than reported by Black et al. (1963) and Perkins, Goode, Wilder \& Henson (1965), but greater than reported by Restall (1966). The minimum di-oestrous levels appear to be lower, and occur later in the cycle, than reported by these authors.

Maximum fluid flow through the ovarian end of the Fallopian tube occurred about $24 \mathrm{hr}$ after the onset of oestrus. Although the time at which ovulation occurs in the ewe is somewhat variable (Asdell, 1946), it is probable that this peak flow of fluid in the ovarian direction occurs near the time of ovulation. This movement of fluid would, therefore, be in the opposite direction to that of the ovum in its passage through the fimbria and down into the ampulla. On this basis it appears that fluid movement plays little part in the mechanism of ovum 
'pick-up' and subsequent transport. It should be emphasized, however, that the measurements of fluid collected were made at 24-hourly intervals, thus, any transient change in the direction of flow, at or after the time of ovulation, would not be detected. Any such reversal, if it were to occur, is probably not important in ovum 'pick-up' since ova may enter the fimbrial portion of the Fallopian tube in the rabbit previously ligated at the abdominal tubal ostium (Clewe \& Mastroianni, 1958). Thus it seems likely that cilia (Borell, Nillsson \& Westman, 1957) and/or muscular contractions (Greenwald, 1963) are capable of projecting the ovum forward against the opposing current. It is also feasible that the cumulus matrix, known to surround the pre-ovulatory ovum, may facilitate the action of cilia in moving the ovum and preventing its loss into the abdominal cavity. Some support for this possibility is provided by the observation that glass beads are rejected if placed on the fimbria of the ewe (D. R. Lang, personal communication) and a cumulus coating has facilitated the movement of resin spheres down the ampulla of the ewe (Bennett \& Rowson, 1961).

In contrast to the flow of fluid through the ovarian end, maximum flow through the utero-tubal junction and into the uterus occurred about 3.9 days $(94 \mathrm{hr})$ after the onset of oestrus. Since ova enter the uterus between 77 and $96 \mathrm{hr}$ after the onset of oestrus in the ewe (Clarke, 1934) it is probable that passage of the ovum into the uterus coincides with this period of maximum flow. The gradual increase in isthmic flow over Days 1,2 and 3 is probably indicative of a gradual decline in the occlusive mechanism in the isthmus, thus permitting passage of fluid through the utero-tubal junction and into the uterus. It is also noteworthy that the occlusion is not complete even at the period of maximum follicular activity and presumably high levels of endogenous oestrogen.

The mechanism preventing the entry of tubal fluid into the uterus has not been determined, but may be due to oestrogen-induced oedema and flexure of the utero-tubal junction (Edgar \& Asdell, 1960) or a function of the isthmus itself (Black \& Davis, 1962). On Day 4 of the oestrous cycle, this occlusion ceases to exist and probably an increasing proportion of fluid of ampulla origin passes through the utero-tubal junction. Considering the difference in lumen size and pressures between the ampulla and isthmus (Brundin, 1964) some propelling mechanism would appear essential to direct fluid down the isthmus at this time. Whether this is a change in the direction (WintenbergerTorrés, 1961) or change in frequency and amplitude of muscle contractions in the isthmus (Greenwald, 1963) remains to be clarified.

The origin of the red colouration in the maximum isthmic flow remains unknown, but significantly none of this colouration ever appeared in the ampullar flow. This presumably indicates that movement in the ovarian direction from the distal isthmus was not taking place, in which case uterine contractions may play a role in the movement of fluid towards the ovary.

The factors causing the wide variation between cycles of individual animals in volume of fluid secreted, ampullar flow and isthmic flow, over each oestrous cycle, remain to be examined. The possibility exists that much of this is due to variability in the number of follicles and corpora lutea functioning during any 
given oestrous cycle and in consequence the level of oestrogen and progesterone circulating (e.g. Edgar \& Ronaldson, 1958).

The method of cannulation described provides evidence on the pattern of fluid secretion and movement in the Fallopian tube but does so within certain limitations. Apart from the presence of the cannula, which apparently caused no morphological changes in the epithelium, ligation at each end of the tube prevents the possible entry of fluid from other sources. The influx of uterine and peritoneal fluid is known to occur while follicular fluid may also contribute during the process of ovulation. The extent to which these fluids contribute towards tubal secretion and its influence on the transport of spermatozoa and ova remains to be clarified.

\section{ACKNOWLEDGMENTS}

The authors wish to thank Dr F. R. M. Cockrem for provision of facilities and advice on the analysis of results, Professor D. S. Flux and Dr R. E. Munford for their fruitful discussions, $\mathrm{Mr} \mathrm{D}$. Ward for aid in preparing histological sections, and Mr G. Muir and Mr L. Hawthorne for technical assistance with care of the animals.

The financial assistance of a New Zealand State Services post-graduate bursary to A.R.B. is acknowledged and the work was aided in part by a University Research Committee Grant 64/215.

\section{REFERENCES}

Asdell, S. A. (1946) Patterns of mammalian reproduction. Comstock, Ithaca, New York.

BennetT, J. P. \& Rowson, L. E. A. (1961) The use of radioactive artificial eggs in studies of egg transfer and transport in the female tract. Proc. IVth int. Congr. Anim. Reprod., The Hague, p. 360.

Bjork, L. (1959) Cineradiographic studies on the Fallopian tube in rabbits. Acta radiol. Suppl. 176.

Black, D. L. \& Asdell, S. A. (1958) Transport through the rabbit oviduct. Am. J. Physiol. $192,63$.

Black, D. L. \& Aspell, S. A. (1959) Mechanism controlling entry of ova into the rabbit uterus. $A m$. $\mathcal{F}$. Physiol. 197, 1275.

Black, D. L. \& Davis, J. (1962) A blocking mechanism in the cow oviduct. F. Reprod. Fert. 4, 21.

Black, D. L., Druby, R. T. \& Riesen, J. (1963) Apparatus for the continuous collection of sheep oviduct fluid. 7. Reprod. Fert. 6, 257.

BONNEr, L. (1964) The origin of the oscillations in kymographic tubal insufflation. Int. 7. Fert. 9, 513.

Borell, U., Nillsson, O. \& Westman, A. (1957) Ciliary activity in the rabbit Fallopian tube during oestrus and after copulation. Acta obstet. gynec. scand. 36, 22.

BRUndin, J. (1964) A functional block in the isthmus of the rabbit Fallopian tube. Acta physiol. scand. 60, 295.

Clarke, R. T. (1934) Studies on the physiology of reproduction in the sheep. II. The cleavage stages of the ovum. Anat. Rec. 60, 135 .

Clewe, T. H. \& Mastroianni, L. (1958) Mechanisms of ovum pickup. I. Functional capacity of the rabbit oviduct ligated near the fimbria. Fert. Steril. 9, 13.

Clewe, T. H. \& Mastroianni, L. (1960) A method for continuous volumetric collection of oviduct secretions. 7. Reprod. Fert. 1, 146.

Duncan, D. B. (1955) Multiple range and multiple F Tests. Biometrics, 11, 1.

Edgar, D. G. \& AsDELL, S. A. (1960) The valve-like action of the utero-tubal junction of the ewe. 7. Endocr. 21, 315.

Edgar, D. G. \& Ronaldson, J. W. (1958) Blood levels of progesterone in the ewe. F. Endocr. $16,378$.

Greenwald, G. S. (1961) A study of the transport of ova through the rabbit oviduct. Fert. Steril. $12,80$.

Greenwald, G. S. (1963) In vivo recording of intralumenal pressure changes in the rabbit oviduct. Fert. Steril. 14, 666.

Harper, M. J. K., BennetT, J. P., Boursnell, J. C. \& Rowson, L. E. A. (1960) An autoradiographic method for the study of egg transport in the rabbit Fallopian tube. J. Reprod. Fert. 1, 249. 
Perkins, J. L., Goode, L., Wilder, W. A. \& Henson, D. B. (1965) Collection of secretions from the oviduct and uterus of the ewe. 7. Anim. Sci. 24, 383.

RADFORD, H. M. \& WATSON, R. H. (1955) Changes in the vaginal contents of the merino ewe throughout the year. Aust. 7. agric. Res. 6, 431.

Restalt, B. J. (1966) The Fallopian tube of the sheep. II. The influence of progesterone and oestrogen on the secretory activities of the Fallopian tube. Aust. F. biol. Sci. 19, 187.

Westman, A. (1926) A contribution to the question of the transit of the ovum from ovary to uterus in rabbits. Acta obstet. gynec. scand. 5, 1.

WiNTENBerger, S. (1953) Recherches sur les relations entre l'œuf et le tractus maternal pendant les premiers stades du développement chez les mammifères. Etude de la traversée de l'oviducte par l'œuf fécondé de brebis. Annls Inst. nain. Rech. agron., Paris, D, 3, 269.

Wintengerger-TorRés, S. (1961) Mouvements des trompes et progression des œufs chez la brebis. Annls Biol. anim. Biochim. Biophys. 1, 121. 